\title{
Malignant Tumors of the Central Nervous System in Kazakhstan: Component Analysis of Incidence Dynamics
}

\author{
Nurbek Igissinov ${ }^{1,2 *}$, Serik Akshulakov¹, Talgat Kerimbayev', Yerzhan \\ Adilbekov $^{1}$, Nurgul Aldiyarova ${ }^{1}$, Alexandr Rakhimbekov ${ }^{3}$, Gulnur Akpolatova ${ }^{4}$, \\ Dinar Tarzhanova ${ }^{4}$
}

\begin{abstract}
The paper presents the incidence rates of malignant tumors of the central nervous system assessed by the component analysis. The data on primary registered cases of malignant tumors of the central nervous system in the country were used as the material of the study for the period from 2004 to 2011 . A general trend of increase in the number of patients with malignant tumors of the central nervous system in Kazakhstan was determined and the potential of their increase was evaluated, which can be due to changes in the morbidity risk and age specifics, as well as the increase in population.
\end{abstract}

Keywords: Component analysis - malignant tumors - CNS - incidence - the expected number of patients

Asian Pac J Cancer Prev, 16 (6), 2289-2295

\section{Introduction}

The incidence rate of malignant tumors of the central nervous system (CNS) is not so high and is not in the leading positions of the structure of cancer pathology. According to the International Agency for Research on Cancer, there are about 14 million registered malignant tumors in the world each year, and approximately 256,000 cases occur in malignant tumors of CNS, which is equal to $1,8 \%$ (Ferlay et al., 2014). However the increase in the incidence of CNS tumors is observed in many countries in recent decades, and correspondingly it is the problem of public health and medicine due to the unfavorable prognosis of the disease.

Numerous studies point to the growth of CNS malignant tumors (Helseth, 1995; Polednak, 1996; Kuratsu et al., 1997; Christensen et al., 2003; Hess et al., 2004; Lonn et al., 2004; Johannesen et al., 2004; Hoffman et al 2006; Mehrazin et al., 2006; Pirouzmand et al., 2007; Yeole, 2008; Deltour et al., 2009; Li-Xiang Ding et al., 2011; Manoharan et al., 2012; Seyed Behzad Jazayeri et al., 2013), especially among older ages (Grieg et al., 1990; Lowry et al., 1998; Kuratsu et al., 2001) and children (Smith et al., 2000; Cho et al., 2002; Wiangnon et al., 2003, McKinney, 2004; Saima Nasir et al., 2010). The results of these studies show many unresolved issues related with the epidemiology of this type of cancer.

Epidemiological studies of CNS malignancies which held in Kazakhstan (Igissinov et al., 2013) show that the dynamics of morbidity are rising, whereas no component analysis was carried out. Component analysis of the dynamics of malignant tumors in Kazakhstan has been studied as a whole for all localizations (Igissinov et al., 2012) and esophageal cancer (Igissinov et al., 2013).

Hence, this study was conducted considering that the study of the incidence of CNS malignant tumors in dynamics by the component analysis has the certain theoretical and practical significance.

\section{Materials and Methods}

The main source of information on the incidence was the data of the cancer care facilities on primary registered cases of MT CNS in the whole country and the data of the Agency of the Republic of Kazakhstan on the dead from MT CNS. Data on the population in the corresponding age and gender groups for the studied years were obtained from the official website of the Committee on Statistics/ Ministry of National Economy of the Republic of Kazakhstan (www.stat.gov.kz).

The dynamics of the MT CNS incidence of Kazakhstan population was investigated using the component analysis guidelines of V. Dvoirin and E. Axel (Dvoirin et al., 1987). This method of dynamics analysis of the MT CNS incidence on the territory of Kazakhstan allows breaking down an increase of incidence into components related to the same population, but in different time periods. There are seven components of the MT CNS incidence. The first three components are related to the changes in population, age structure, and the combined effect of these factors, and the 4-th component is about changes in the risk of the MT CNS incidence rate only. The other 3 
components related to the risk of the MT CNS incidence with population growth, changing of age structure and the influence of all three factors. Many researchers (Starinsky, et al., 2005; Poddubnaya et al., 2007; Kudryavtsev et al., 2008) understand the term «at risk to get sick» as the full range of causes that can lead to an increase, a decrease or stabilization in the incidence. Therefore, last four components associated with increased risk of disease.

The component method is used to analyze the dynamics of the MT CNS incidence of Kazakhstan population from 2004 to 2011. Mathematical calculations of the component analysis of the dynamics of the MT CNS incidence of Kazakhstan population are presented in the corresponding Tables.

\section{Results and Discussion}

The component method of analysis of the dynamics of the MT CNS incidence of Kazakhstan population in 2004 to 2011 is given in Tables 1 and 2. Analysis of the MT CNS incidence in dynamics showed the growth of indicators, while the overall increase in 2011 compared to 2004 was $\mathrm{T}=+0.550 / 0000$, and as shown in Table 1 , the growth of indicators largely depended on the changes in the morbidity risk $(\Sigma=\Delta \mathrm{P}=+0.530 / 0000)$.

As it was already established, trend of the MT CNS incidence in the entire population over the study period tended to increase $(\mathrm{T}=+0.9 \%)$. In this case, attention is drawn to changes in the number of patients with MT CNS, as the expected number of registered cases in the country 2011 was supposed to be about 558 patients, but in fact there were 641 new cases. Thus, based on the analysis of the dynamics of the absolute number of patients with MT CNS in the country for the years 2004-2011, we can assume that each year on the average about 20 cases of MT CNS are not recorded (see Table 3 (+88-65+101-74 $+50-22+63) / 7=20)$ ). Also, these numbers would increase on average by $86((+88+23+124+50+100+78+141) / 7=86)$ patients with a recalculation on their expected or theoretical number of patients with MT CNS, which is more than 4 times higher than the expected number of unreported cases (Table 3).

Such epidemiological patterns according to which population growth and changes in the age structure are lead to the simultaneous increase of the number of patients are recognized worldwide. And these patterns are observed in our country too.

The research allows us to conclude that changes in the dynamics of the number of patients with MT CNS in Kazakhstan can generally be related to the following factors (Table 2):

i) Population growth $\Delta \mathrm{H}=+35.4 \%$.

ii) Changes in the age structure of the population $\Delta \mathrm{B}=+5.5 \%$.

iii) Combined effect of changes in population size and age structure $\triangle \mathrm{HB}=+0.5 \%$.

iv) Changes in the risk of getting sick $\mathrm{P}=+56.6 \%$.

v) Combined effect of changes in the risk of getting sick and population $\triangle \mathrm{HP}=+5.6 \%$.

vi) Combined effect of changes in the risk of getting sick and age structures $\Delta \mathrm{VR}=-3.3 \%$.

vii) Combined effect of the changes in the risk of getting sick, the population and its age structure $\triangle \mathrm{HBP}=$ $-0,3 \%$.

The total increase in the absolute number of cases is equal to the sum of the components: $\mathrm{n}_{2}-\mathrm{n}_{1}=50+8+80+1+8-5$ $1=+141$ or $+28.2 \%$ related to the initial number of patients $(141 \div 500 \times 100=28.2 \%)$.

Accordingly, the components of the growth in percentage of the initial level will be equal to:
A) $(10.0 \%+1.5 \%+0.2 \%+16.0 \%)=11.7 \%$
B) $(16.0 \%+1.6 \%-0.9 \%-0.1 \%)=16.6 \%$
$(\mathrm{A}+\mathrm{B})(11.7 \%+16.6 \%)=28.2 \%$

Thus, MT CNS in Kazakhstan is characterized by growth in the number of cases due to changes in total population and its structure $(+11.7 \%$ of the total growth, which is equal to $+28.2 \%$ ). There is high potential of real increase in the number of cases $(+16.0 \%)$.

Components are categorized into three classes, one of

Table 1. The Component Analysis of the CNS Cancer Incidence Increase in Kazakhstan from 2004 Till 2011

\begin{tabular}{|c|c|c|c|c|c|c|c|c|c|}
\hline \multirow{3}{*}{ Age (i) } & \multirow{2}{*}{\multicolumn{2}{|c|}{$\begin{array}{l}\text { Age structure of } \\
\text { the population } \\
\qquad\left(S i j=N_{i j} \div N_{j}\right)\end{array}$}} & \multirow[b]{3}{*}{$\begin{array}{l}\text { An increase } \\
\text { of structural } \\
\text { indicators } \\
\left(S_{i 2}-S_{i 1}\right) \\
(3)-(2)\end{array}$} & \multicolumn{2}{|c|}{$\begin{array}{l}\text { CNS cancer } \\
\text { incidence }\end{array}$} & \multirow[b]{3}{*}{$\begin{array}{l}\text { general } \\
\left(P_{i 2}-P_{i 1}\right) \\
(6)-(5)\end{array}$} & \multirow{2}{*}{\multicolumn{3}{|c|}{$\begin{array}{l}\text { Increase of incidence } \\
\text { g in connection with the change }\end{array}$}} \\
\hline & & & & \multirow[b]{2}{*}{$\begin{array}{l}2004 \\
\left(P_{i 1}\right)\end{array}$} & \multirow[b]{2}{*}{$\begin{array}{l}2011 \\
\left(P_{i 2}\right)\end{array}$} & & & & \\
\hline & $\begin{array}{c}2004 \\
\left(S_{i 1}\right)\end{array}$ & $\begin{array}{c}2011 \\
\left(S_{i 2}\right)\end{array}$ & & & & & $\begin{array}{l}\text { age structure } \\
\text { of the } \\
\text { population } \\
(4) \times(5)\end{array}$ & $\begin{array}{l}\text { a risk to get } \\
\text { sick }(2) \times(7)\end{array}$ & $\begin{array}{l}\text { age structure of } \\
\text { the population } \\
\text { and a risk to get } \\
\text { sick }(4) \times(7)\end{array}$ \\
\hline 1 & 2 & 3 & 4 & 5 & 6 & 7 & 8 & 9 & 10 \\
\hline$<30$ & 0.5240 & 0.5189 & -0.0051 & 1.4 & 1.7 & +0.3 & -0.007 & 0.137 & -0.001 \\
\hline $30-39$ & 0.1454 & 0.1469 & +0.0015 & 3.2 & 3.6 & +0.4 & +0.005 & 0.056 & 0.001 \\
\hline $40-49$ & 0.1404 & 0.1314 & -0.0090 & 4.7 & 5.2 & +0.6 & -0.042 & 0.079 & -0.005 \\
\hline $50-59$ & 0.0827 & 0.1034 & +0.0207 & 9.5 & 9.0 & -0.5 & +0.196 & -0.038 & -0.010 \\
\hline $60-69$ & 0.0640 & 0.0510 & -0.0130 & 8.9 & 11.3 & +2.4 & -0.116 & 0.157 & -0.032 \\
\hline $70+$ & 0.0435 & 0.0484 & +0.0049 & 3.2 & 6.5 & +3.3 & +0.016 & 0.144 & 0.016 \\
\hline Total & $\sum S_{i 1}=1.0$ & $\sum S_{i 2}=1.0$ & & $\mathrm{P}_{1}=3.34$ & $\mathrm{P}_{2}=3.90$ & +0.55 & $\sum=\Delta_{B}=+0.05$ & $\sum=\Delta_{\mathrm{p}}=+0.53$ & $\sum=\Delta_{\mathrm{BP}}=-0.03$ \\
\hline
\end{tabular}




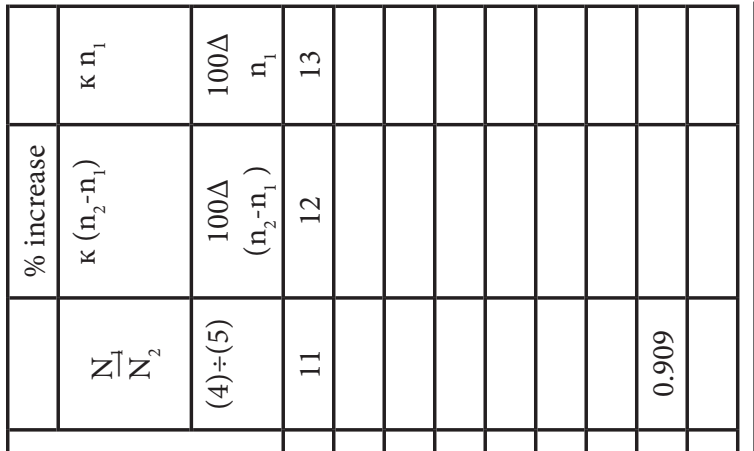

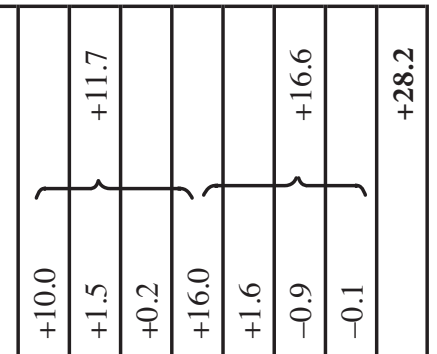

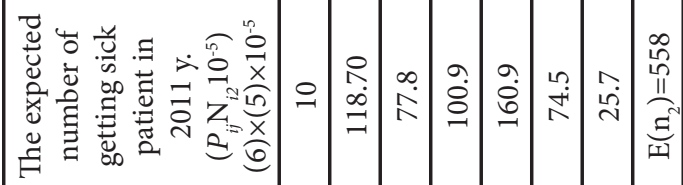
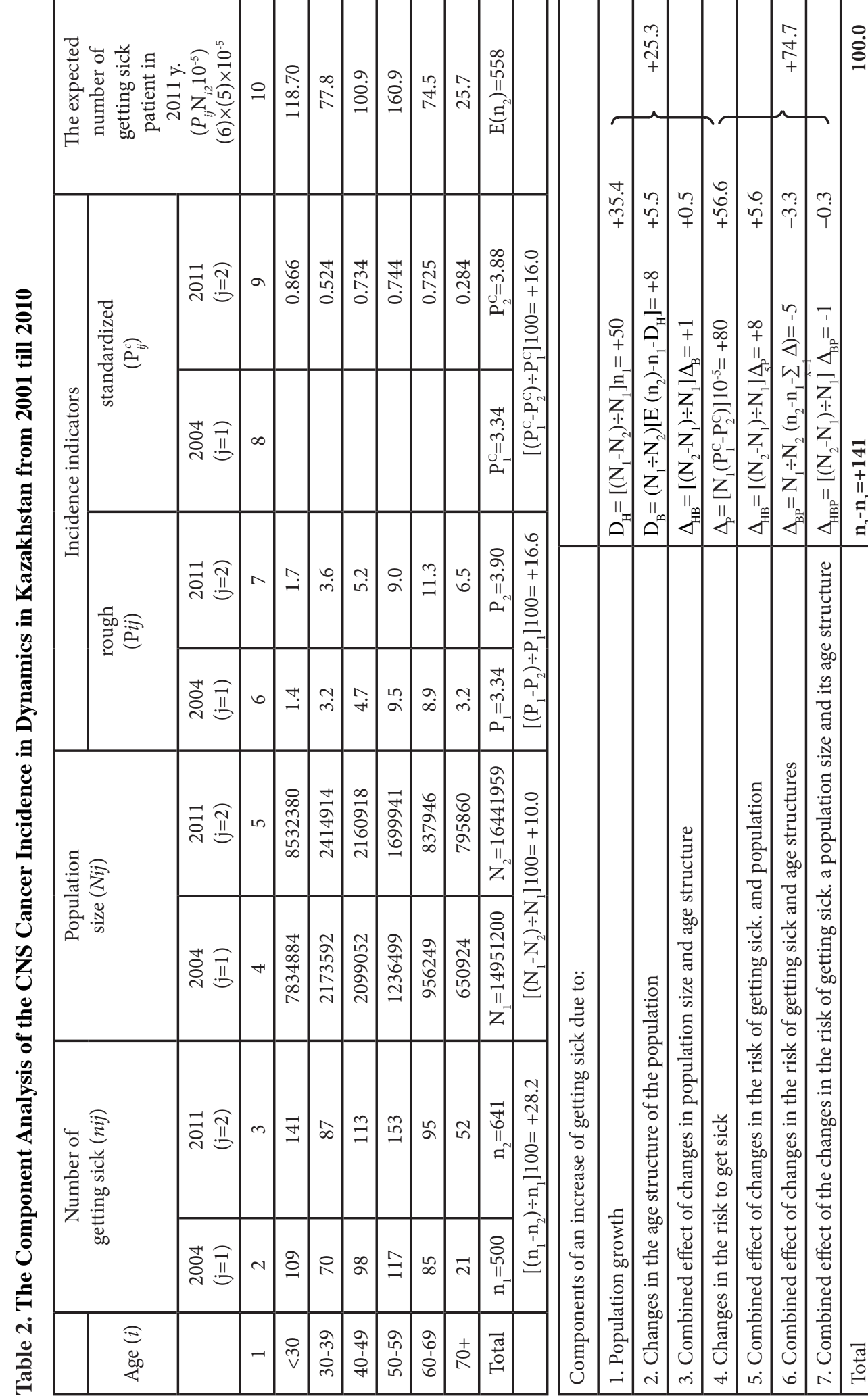

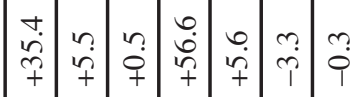

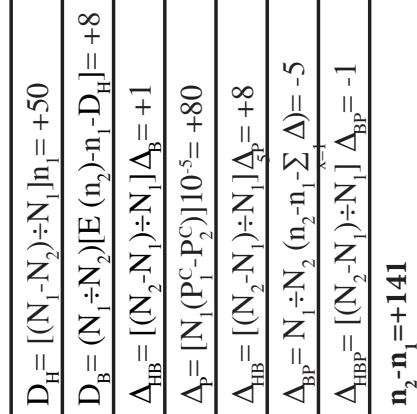

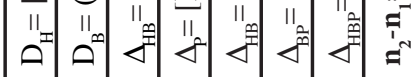

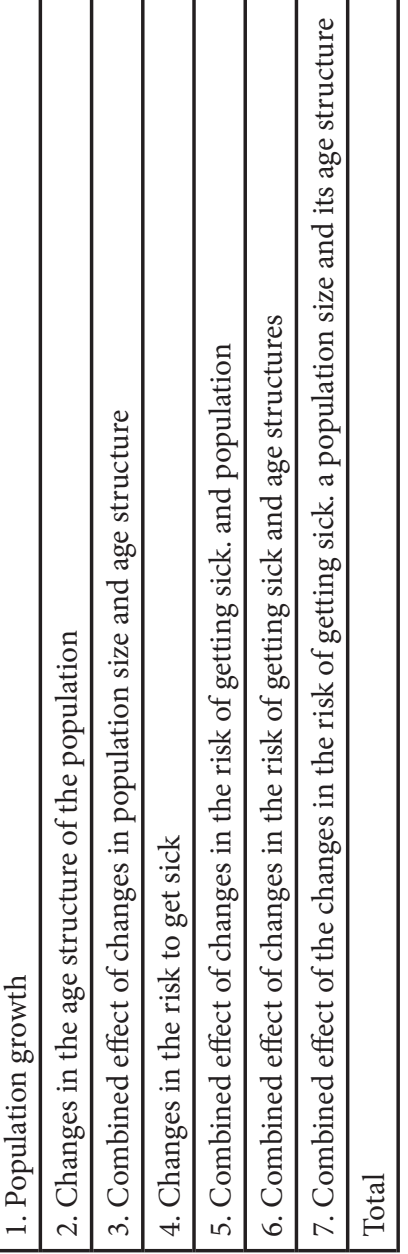


Table 3. Absolute Number of CNS Cancer and its Meaning in Kazakhstan

\begin{tabular}{|l|c|c|c|c|c|c|c|c|}
\hline CNS cancer & 2004 & 2005 & 2006 & 2007 & 2008 & 2009 & 2010 & 2011 \\
\hline Registered patients (X) & 500 & 588 & 523 & 624 & 550 & 600 & 578 & 641 \\
\hline $\begin{array}{l}\text { Increase or decrease in the abso- } \\
\text { lute number compared to previous } \\
\text { year }\end{array}$ & - & +88 & -65 & +101 & -74 & +50 & -22 & +63 \\
\hline $\begin{array}{l}\text { Increase (decrease) in the absolute } \\
\text { number compared to 2004 }\end{array}$ & - & +88 & +23 & +124 & +50 & +100 & +78 & +141 \\
\hline $\begin{array}{l}\text { Growth (increase) rate compare to } \\
\text { previous year (\%) }\end{array}$ & - & +17.6 & -11.1 & +19.3 & -11.9 & +9.1 & -3.7 & +10.9 \\
\hline $\begin{array}{l}\text { Growth (increase) rate compare to } \\
\text { 2004 (\%) }\end{array}$ & - & +17.6 & +4.6 & +24.8 & +10.0 & +20.0 & +15.6 & +28.2 \\
\hline Population size (thousand) & 14,951 & 15,075 & 15,219 & 15,397 & 15,572 & 15,777 & 16,205 & 16,442 \\
\hline $\begin{array}{l}\text { Expected number }\left(\mathrm{X}_{\mathrm{ex}} \text { ) compared }\right. \\
\text { to 2004 }\end{array}$ & 500 & 504 & 509 & 515 & 521 & 528 & 542 & 550 \\
\hline $\begin{array}{l}\text { Difference between the expected } \\
\text { and registered absolute number } \\
\left(\mathrm{X}_{\text {ex }}-\mathrm{X}_{\mathrm{r}} \text { ) }\right.\end{array}$ & - & 84 & 14 & 109 & 29 & 72 & 36 & 91 \\
\hline
\end{tabular}

which reflects a different kind of changes in the population $(\Delta H+\Delta B+\Delta H B)$, the second relates to increase of the risk of getting sick only $(\triangle P)$, and the third presents the relationship between these factors $(\Delta H R+\Delta B R+\Delta H B R)$. Therefore, in order to characterize the cumulative effect of changes in the population or the risk of getting sick to the components of the $1^{\text {st }}$ and $2^{\text {nd }}$ classes, there should be added the effect of the $3^{\text {rd }}$ class components' impact:
i) $(\Delta \mathrm{H}+\Delta \mathrm{B}+\Delta \mathrm{HB})+(\Delta \mathrm{HR}+\Delta \mathrm{BR}+\Delta \mathrm{HBR})$

ii) $\triangle \mathrm{P}+(\Delta \mathrm{HR}+\Delta \mathrm{BR}+\Delta \mathrm{HBR})$

If the total increase in the number of cases of MT CNS (141) consider as $100 \%$, the increase which is in anyway associated with the risk of the disease progression will be $+58.6 \%[(+16.0+1.6-0.9-0.1) \div 28.2 \times 100]$, and with the "clear" increase of risk $+56.6 \%$.

Different componential structures of MT CNS at different periods of time or in different population groups in the same periods of time may provide important information for the formation of epidemiological hypotheses about the possible causal role of environmental factors.

Thus, the number of patients with MT CNS in Kazakhstan is increasing. The increase is associated with the population growth, the combined effect of changes in population and its age structure, changes in the risk of getting sick, the combined effect of changes in the risk of getting sick and the age structure of the population. The results of the component analysis of dynamics of the MT CNS incidence in Kazakhstan are recommended to use in planning the anticancer activities due to MT CNS.

\section{References}

Cho K, Wang K, Kim S, et al (2002). Pediatric brain tumors: statistics of SNUH, Korea (1959-2000). Childs Nerv Syst, 18, 30-7.

Christensen HC, Kosteljanetz M, Johansen C (2003). Incidences of gliomas and meningiomas in Denmark, 1943 to 1997. Neurosurgery, 52, 1327-33.

Deltour I, Johansen C, Auvinen A, et al (2009). Time trends in brain tumour incidence rates in Denmark, Finland, Norway, and Sweden, 1974-2003. J Natl Cancer Inst, 101, 1721-4.

Ferlay J, Soerjomataram I, Ervik M, et al (2012). Cancer incidence and mortality worldwide: IARC cancerbase No. 11 [Internet]. Lyon, France: international agency for research on cancer; 2013.

Grieg NH, Ries LG, Yancik R, Rapoport SI (1990). Increasing annual incidence of primary malignant brain tumors in the elderly. J Natl Cancer Inst, 82, 1621-4.

Helseth A (1995). The incidence of primary central nervous system neoplasms before and after computerized tomography availability. J Neurosurg, 83, 999-1003.

Hess KR, Broglio KR, Bondy ML (2004). Adult glioma incidence trends in the United States, 1977-2000. Cancer, 101, 2293-9.

Hoffman S, Propp JM, McCarthy BJ (2006). Temporal trends in incidence of primary brain tumors in the United States, 1985-1999. Neuro-Oncol, 8, 27-37.

Igissinov N, Akshulakov S, Igissinov S, et al (2013). Malignant tumours of the central nervous system in Kazakhstan -incidence trends from 2004-2011. Asian Pac J Cancer Prev, 14, 4181-6.

Igissinov S, Igissinov N, Moore M et al (2013). Component analysis of esophageal cancer incidence in Kazakhstan. Asian Pac J Cancer Prev, 14, 1945-9.

Igissinov S, Igissinov N, Seytkazina G (2012). Component analysis of the incidence of malignant tumors of the population of Kazakhstan from 1999 to 2010 . Oncol Radiol Kazakhstan, 1, 3-8.

Johannesen TB, Angell-Andersen E, Tretli S, et al (2004). Trends in incidence of brain and central nervous system tumors in Norway, 1970-1999. Neuroepidemiol, 23, 101-9.

Keene DL, Hsu E, Ventureyra E (1999). Brain tumors in childhood and adolescence. Pediatr Neurol, 20, 198-203.

Kudryavtsev I, Balenko O (2008). Component analysis of cancer incidence in navoi region. materials $\mathrm{v}$ congress of oncologists and radiologists CIS tashkent, 21.

Kuratsu J, Takeshima H, Ushio Y (2001). Trends in the incidence of primary intracranial tumors in Kumamoto, Japan. Int $J$ Clin Oncol, 6, 183-91.

Kuratsu J, Ushio Y (1997). Epidemiological study of primary intracranial tumours in elderly people. J Neurol Neurosurg Psychiatr, 63, 116-8.

Li-Xiang Ding, You-Xin Wang (2011). Increasing incidence of 

brain and nervous tumours in urban Shanghai, China, 19832007. Asian Pac J Cancer Prev, 12, 3319-22

Lönn S, Klaeboe L, Hall P, et al (2004). Incidence trends of adult primary intracerebral tumors in four Nordic countries. Int $J$ Cancer, 108, 450-5.

Lowry JK, Snyder JJ, Lowry PW (1998). Brain tumors in the elderly: recent trends in a Minnesota cohort study. Arch Neurol, 55, 922-8.

Manoharan N, Julka PK, Rath GK (2012). Descriptive epidemiology of primary brain and CNS tumors in Delhi, 2003-2007. Asian Pac J Cancer Prev, 13, 637-40

McKinney PA (2004). Brain tumours: incidence, survival, and aetiology. J Neurol Neurosurg Psychiatr, 75, 12-7.

Mehrazin M, Rahmat H, Parvin Yavari (2006). Epidemiology of primary intracranial tumors in Iran, 1978-2003. Asian Pac J Cancer Prev, 7, 283-8.

Pirouzmand F, Sadanand V (2007). The incidence trends of primary brain tumors in Saskatchewan from 1970 to 2001. Can J Neurol Sci, 34, 181-6.

Poddubnaya I, Axel E, Kipriyanova N, et al (2007). Component analysis of cancer incidence population (Yakutsk, 19902003). Siberian J Oncol, 2, 55-63.

Polednak AP (1996). Interpretation of secular increases in incidence rates for primary brain cancer in Connecticut adults, 1965-1988. Neuroepidemiol, 15, 51-6.

Saima Nasir, Bibi Jamila, Samina Khaleeq (2010). A retrospective study of primary brain tumors in children under 14 years of age at PIMS, Islamabad. Asian Pacific J Cancer Prev, 11, 1225-7.

Seyed Behzad Jazayeri, Vafa Rahimi-Movaghar, Farhad Shokraneh, et al (2013). Epidemiology of primary CNS tumors in Iran: a systematic review. Asian Pac J Cancer Prev, 14, 3979-85.

Smith MA, Freidlin B, Ries LA, Simon R (2000). Increased incidence rates but no space-time clustering of childhood astrocytoma in Sweden, 1973-1992: a population-based study of pediatric brain tumors. Cancer, 88, 1492-3.

Starinsky V, Poddubnaya I, Axel E, et al (2005). Component analysis of malignant tumors of the population of the republic of Sakha (Yakutia) in 1989-2001. Russian J Oncol, 1, 38-41.

Wiangnon S, Kamsa-ard S, Jetsrisuparb A, et al (2003). Childhood cancer in Thailand: 1995-1997. Asian Pac J Cancer Prev, 4, 337-43.

Yeole B (2008). Trends in the brain cancer incidence in India. Asian Pac J Cancer Prev, 9, 267-70. 
Nurbek Igissinov et al 
DOI:http://dx.doi.org/10.7314/APJCP.2015.16.6.2289

Malignant Tumors of the Central Nervous System in Kazakhstan: Component Analysis of the Dynamics of Incidence 